\title{
Ophthalmic Cream Dosage Form
}

National Cancer Institute

\section{Source}

National Cancer Institute. Ophthalmic Cream Dosage Form. NCI Thesaurus. Code C91159.

A cream intended for administration in or around the eye. 